\title{
E-Challan: Online Traffic Rules Violation Penalty and Management System
}

\author{
Allokik Pranshu \\ School of Computer Science and \\ Engineering, VIT University \\ Vellore-632014, Tamil Nadu, India
}

\author{
Sanjay Kumar ljju \\ School of Computer Science and \\ Engineering, VIT University \\ Vellore-632014, Tamil Nadu, India
}

\author{
Swarnalatha P., PhD \\ School of Computer Science and \\ Engineering, VIT University \\ Vellore-632014, Tamil Nadu, India
}

\begin{abstract}
The aim of this paper is to develop an online platform to facilitate the drivers and the traffic police to manage the penalties for traffic violations. E-Challan System is the online platform aimed at providing a wide range of support in managing and monitoring the traffic penalties, helping users regarding the problems they face in paying for their challan. The E-challan System is basically an interaction between Police and drivers easily through an online platform or an app. This project prototype describes how challan becomes easy for users through keeping it online. The online platform aims to reduce the paperwork, manual process and increase the convenience for the users.
\end{abstract}

\section{General Terms}

Web Application, Traffic Penalty, E- Governance.

\section{Keywords}

E-penalty, E-challan, Traffic Violation

\section{INTRODUCTION}

Governance is a challenge in a country as diverse, vast and rapidly developing as India. India needs a new and latest technology for large-scale transformation and implementation of government plans. While India is among the fastest developing economies in the world, India's equitable growth remains a critical imperative. This project is an attempt in this very direction of e-governance for a country like India with a large population and high density.

India's road network has grown at an annual rate of $4 \%$ since 1951. Along with the rural and urban population density the density of roads has risen in India. The rising population has resulted in more vehicles on roads. This has led to a high rate of accidents. One of the major reasons for the high number of accidents on the road is that traffic rules are violated and not followed. According to a survey, $78 \%$ of the accidents happen due to violation of traffic rules by the driver such as speeding, driving under the influence of alcohol or drugs, and hit and run cases.

India needs a highly regulated foolproof system of governance to prevent these avoidable accidents and manage the traffic on the roads. A system which makes the people follow the rules and drive safely, without violating any rules. E-Challan is that foolproof regulated system. E-Challan is an online Egovernance system to facilitate the traffic managers to manage the traffic violation as well as for the drivers to manage the penalties. E-Challan provides a wide range of support needed for managing and monitoring traffic penalties. It is also a type of decentralized information system which allows all the stakeholders to access the needed information anytime anywhere. In the following sections a detailed methodology along and a comparative study with the past works is done to provide a detailed overview about the E-Challan system.

This Project is mainly about an e-governance management system which allows different features to the stakeholders related to challan, vehicle details and license details. The Software has different types of users who are dependent on each other for the fully functioning of the application. The Software allows to create and maintain a database containing information about different registered users, their license details and challans issued. The system also maintains a database of vehicles which are registered in the local RTO. This information can be used to verify drivers and in case of any violation of traffic rules to issue a challan to the driver. Also, the software allows the system administrator to access and update the databases when a new driver or vehicle is registered. The system admin also creates initial login credentials for the traffic department personnel. The administrator is the sole authority who can manipulate all the information in these databases.

\section{LITERATURE SURVEY}

A detailed survey of existing projects and models was done to arrive on a foolproof and successful model.

The paper [1] discusses an electronic governance model of electronic challan and traffic penalty system using an integrated existing method of penalty in India.

A similar approach is followed by [2] which implements the model using an automatic challan system using MATLAB. The model captures the image of the vehicle and extracts the number plate of the vehicle which breaches the traffic law. The model further processes to generate an automatic EChallan which can be directly paid by the driver at RTO office or can avail other online payments also. The project mainly focuses on the individual data extraction from multiple databases. The paper [3] discusses the traffic violation detection using computer vision. The model extracts the license plate using a new deep learning network structure which is used to detect and locate the license plate automatically. The vehicle no is detected and the information of the owner is extracted. The information is used to generate an E-Challan and an instant appropriate fine message is sent to the owner. Implementation of the whole model is very efficient and requires very less human intervention. A new approach is suggested by [4] using a picode suggesting an innovative e-challan application using encoding and decoding of the picode. The paper has discussed and illustrated an efficient method to read the picode and generate a challan for the traffic violators using QRcode encoder.

The paper [5] suggests a useful web- based application using a database program that records all the traffic offenses 
committed throughout the nation. It maintains a centralized database to keep the adequate record and provides an online payment facility to the violators. The project is developed using Python, Ajax, MySQL, Php and python.

A novel approach is discussed in the paper [6] proposing an efficient e-challan generation technique using OCR, generating challan using android application. The application works by detecting the plate, then fetching the details from the database and generating the challan. A similar approach is used by [7] suggesting the need of an efficient and smart automated traffic penalty generation system. The authors suggest the retrieval of information of vehicles from the official database using smartphones, by scanning the $Q R$ code. The officer can then generate an e-challan with the app and the challan will be sent to the driver using SMS.

A new IOT based automatic penalty charging approach is suggested by [8]. The authors have used the IOT based approach for development of the solution for violation of traffic rules using microcontrollers, RFID, LCD interfaced with AVR. The proposed system will continuously monitor the vehicles using RFID readers and transceivers, and will automatically generate a challan for violation of any traffic rules. If the driver fails to pay the charges in a given period of time, the regional transport office (RTO) may suspend the license of the driver.

The paper [9] presents a system called TRuVIS (Traffic Rule Violation Information System) which is basically an alert system developed using Arduino, which regulates, monitors and takes action against rule violation by the driver. The system generates a challan and sends the notification to the driver's phone. The application is developed mainly for regulating the horn violation.

The paper [10] discusses the disadvantages of manual echallan generating process, the problem of fake challans, loss to the government and inconvenience caused to the driver. The author suggests a smart automatic e-challan system based on RFID and GPS modules. The system can locate the vehicle using the GPS and the official can generate a challan using the information of the vehicle saved in the database, which will be then sent to the owner of the vehicle using SMS.

\section{METHODOLOGY}

The paper presents a web-application developed with a step by step methodology as discussed below.

\subsection{Define the stakeholders of this web- application.}

There are 3 distinct type of users on the platform namely:

1. Traffic Police Personnel: The registered employee of the traffic police who can issue the challans to the drivers who have violated any traffic rules across the city.

2. Drivers: The licensed people who have been permitted to drive the vehicles across the city and have been issued a challan due to violation of any traffic rules. These people can pay and manage their issued challan on the platform.

3. System Administrator: The system administrator is responsible for the management of accounts of the above users and is responsible for issuing login credentials to the traffic police personnel, and insertion of new vehicle, driver and license details in the database.
Each of the users have been provided with a variety of different functionalities and resources which they can use on the online platform with verified login credentials.

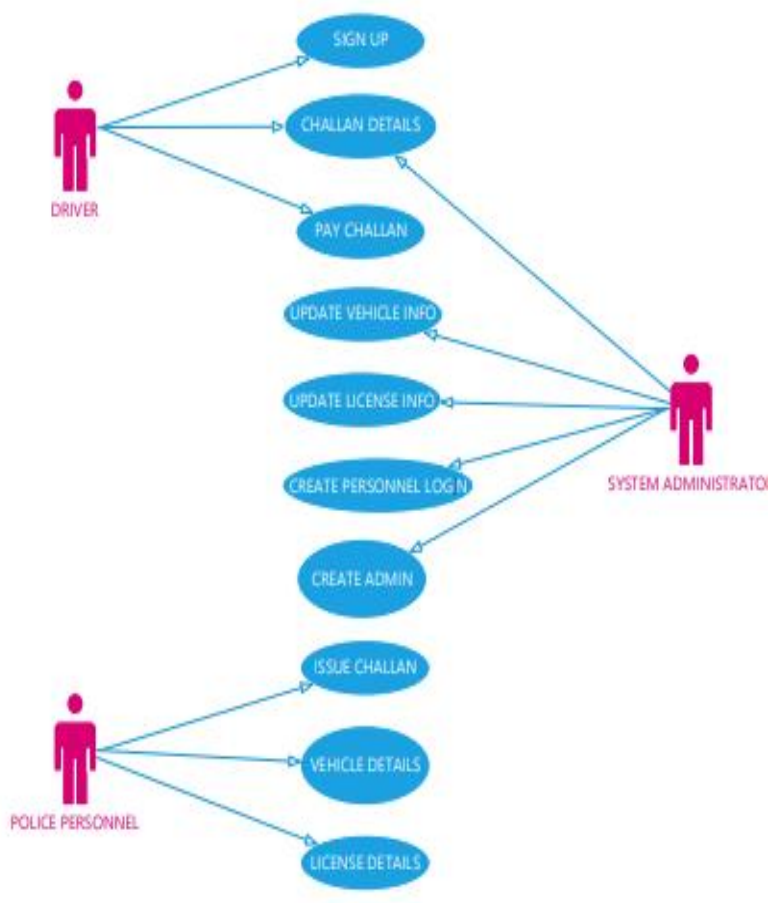

Fig 1: Stakeholders and use case diagram

\subsection{Determining the requirements of the stakeholders}

(A) TRAFFIC POLICE PERSONNEL:

1. The new personnel SHALL be issued an initial login ID and a password by system administrator.

2. The new personnel SHALL be able to generate his/her login ID and a password

3. The personnel SHALL be able to login using his or her ID and password.

4. The personnel SHALL be able to reset his or her password in-case he or she forgets it.

5. The personnel SHALL be able to input the details of the license.

6. The personnel SHALL be able to get the details of the owner of the license.

7. The personnel SHALL be able to input the details of the vehicle.

8. The personnel SHALL be able to get the details of the owner of the vehicle.

9. The personnel SHALL be able to input the details required for issuing the challan like offence, location, time and comments.

10. The personnel SHALL be able to issue a challan successfully.

11. The personnel SHALL be able to see the challan history of the driver.

12. The personnel SHALL be able to see the challans issued by himself or herself. 
(B) DRIVER:

1. A new driver SHALL be able to sign-up himself/herself using his/her general information like his license details, email and phone number.

2. The new driver SHALL be able to generate his/her login ID and a password

3. The driver SHALL be able to login using his or her ID and password.

4. The driver SHALL be able to reset his or her password in-case he or she forgets it.

5. The driver SHALL be able to view his challan history

6. The driver SHALL be able to view the challans issued to him by the traffic personnel.

7. The driver SHALL be able to pay the issued challans due for payment.

\section{(C) SYSTEM ADMINISTRATOR:}

1. The Administrator SHALL be able to login using his or her ID and password.

2. The Administrator SHALL be able to reset his or her password in-case he or she forgets it.

3. The Administrator SHALL be able to generate new admins by issuing them an initial login ID and password.

4. The Administrator SHALL be able to insert the details of the new vehicle registered.

5. The Administrator SHALL be able to insert the details of the new license registered.

6. The Administrator SHALL be able to generate new personnel credentials by issuing them an initial login ID and password.

7. The Administrator SHALL be able to get the details of personnel.

\subsection{Determine the relationships between the different entities and classes.}

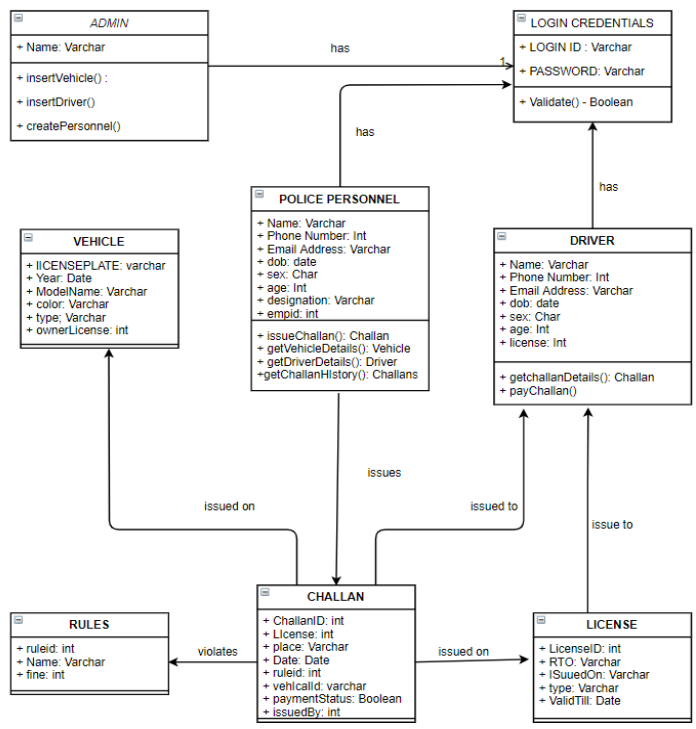

Fig 2: Class Diagram

\subsection{Using Technical Specs develop the web- application.}

The project has used a variety of front and back end frameworks for implementations such as:

1. HTML: For front-end development

2. CSS: For front-end development

3. JS: For animations and display time

4. Php: For front and back end connections, session creation and queries

5. AJAX: With Ajax, web application can send and retrieve data from a server asynchronously without interfering with the display and behavior of the existing page.

6. jQuery: For animations

7. MySQL: Back end development

\section{IMPLEMENTATION AND RESULTS}

The application provides a number of features such as display vehicle details, display driver details, pay challan and issue challan. The core application of the website is to issue and pay challan, working of which is described in the following section.

Step 1: Personnel login:

The traffic police personnel login in the web- application using his credentials. On his desktop he/she can see all the functionalities which can be used by him/her. For issuing the challan the personnel click on the issue challan icon and an issue challan form is opened.

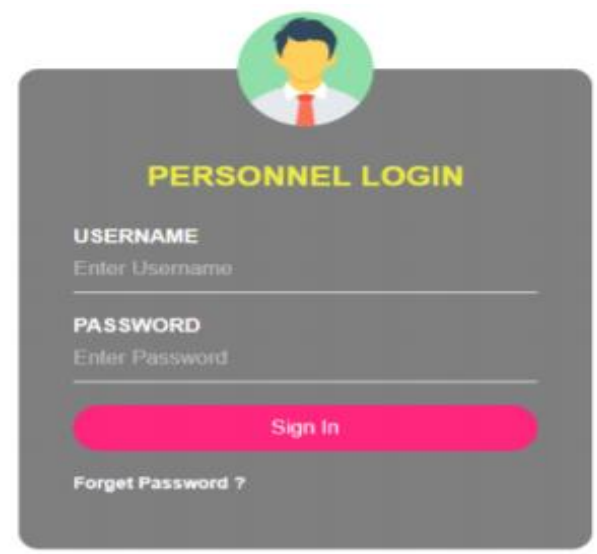

Fig 3: Personnel Login

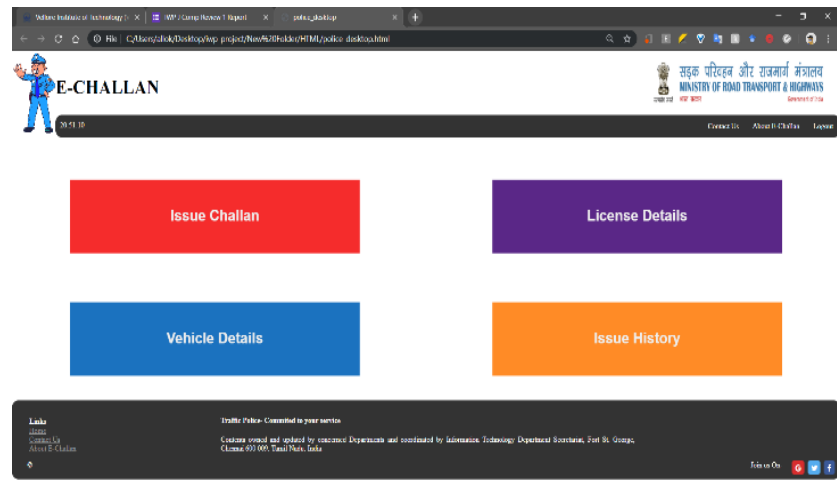

Fig 4: Personnel Desktop 
Step 2: Issue Challan:

The personnel will identify the traffic violator and will enter his/her license no which will display the vehicles registered with the driver. The police personnel can select the vehicle, location and offence from a drop-down list, and then click on the issue challan button to issue the challan. The System will generate the challan and the details will be updated in the database.

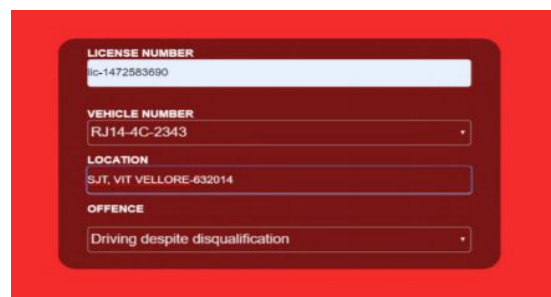

Fig 5: Enter License Number

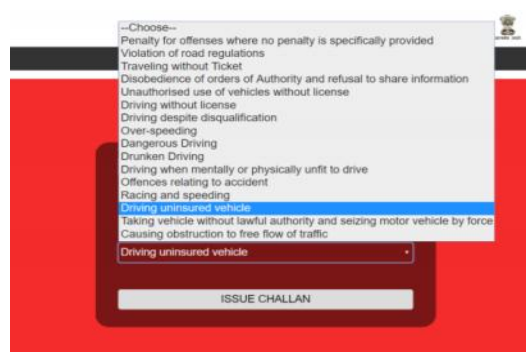

Fig 6: Select Offense

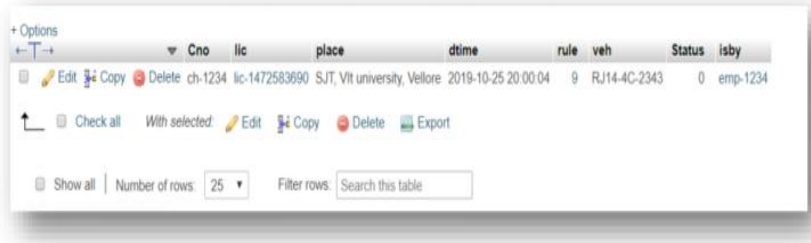

Fig 7: Stored in the database

The next step will be by the driver, to whom the challan has been issued, the driver will go to his/her desktop and pay the challan.
Step 3: Payment of the challan by the Driver:

Similar to traffic personnel the driver will login in the webapplication and will arrive on his/her desktop. By selecting the pay challan icon, all the challans issued to the driver will be displayed, the driver can select the pay button corresponding to the challan he wants to pay, and after successful payment, the challan payment details will be updated in the database.

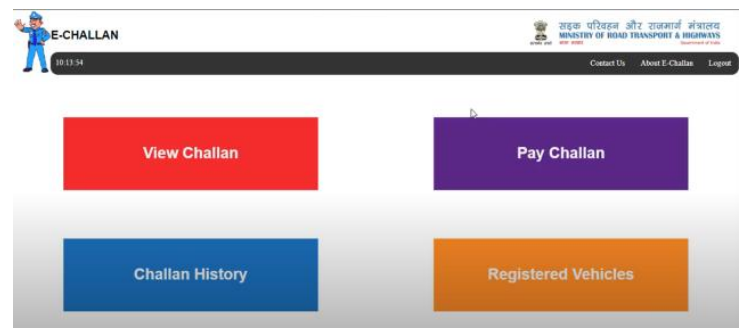

Fig 8: Driver Desktop

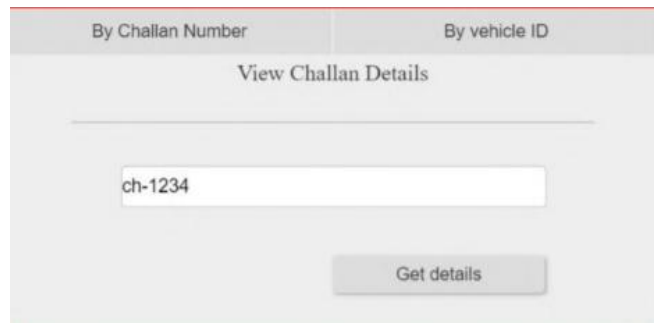

Fig 9: Search Challan

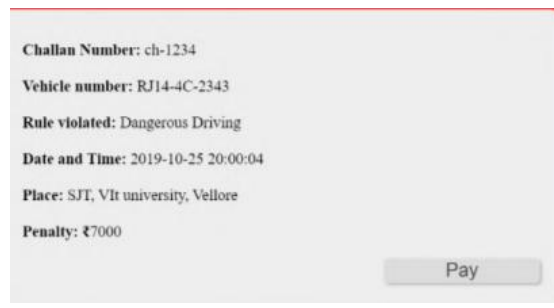

Fig 10: Display of the challan details and

The payment details and the challan status will be updated in the database. 


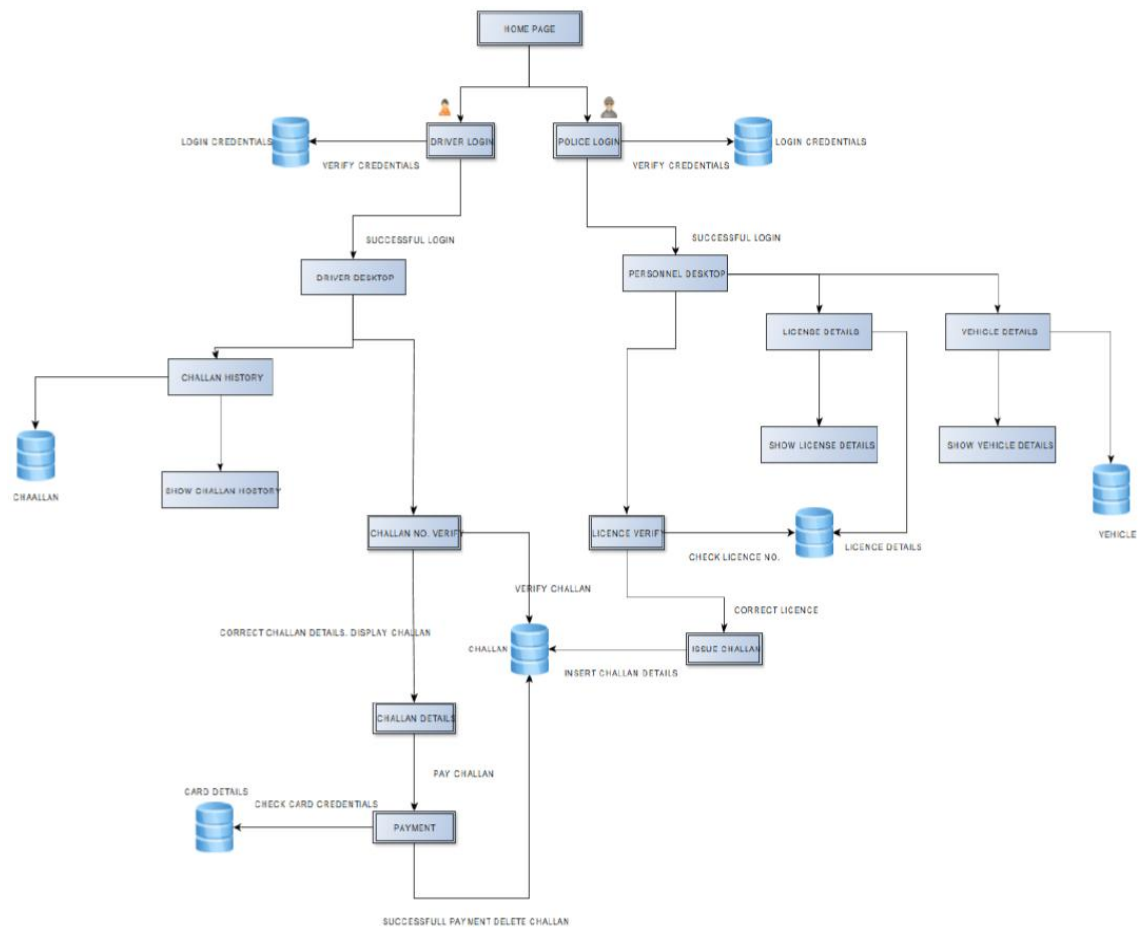

Fig 11: Architecture of the web-application

\section{CONCLUSIONS}

The project mainly focuses on issue and view or pay challan along with details extraction of vehicles, license numbers and challan details. The project can be extended to a full stack functional website in future providing other features such as license creation, RTO vehicle registrations and many more. The system can also be modified by using the latest technologies as discussed in the literature survey like QRcode and RFID scanner. This will limit human intervention and will result in a more efficient model of the existing system.

\section{ACKNOWLEDGMENTS}

The authors are grateful to the VIT University for providing the platform, resources and support for this project. The authors are also grateful to their colleagues, Onkar Sharma, Gagan Deep Singh and Aditya K Rahul for their valuable feedback, constant guidance and support.

\section{REFERENCES}

[1] Goel, S. K., \& Shukla, M. (2018). Enforcement of Automatic Penalty (e-Penalty) to Govern the Traffic Rule Violators in Digitized INDIA Using ICT. In Computational Vision and Bio Inspired Computing (pp. 788-802). Springer, Cham.

[2] Nigam, U., Akhtar, S., Singh, R., Ahmad, S., Kumar, S., \& Ambikapathy, A. (2019). Automatic Traffic Monitoring and E-Challan Generation Using Matlab. Journal of Control \& Instrumentation, 10(1), 911.

[3] Dhage, M. R., Patil, G. V., Mistry, S. J., Tambe, P. N., \& Nankar, P. H. (2019, July). Automatic Traffic E-challan Generation Using Computer Vision. In International Conference on Sustainable Communication Networks and Application (pp. 203-213). Springer, Cham.
[4] Dubey, R. S., \& Warker, K. V. (2017, June). An effective approach for e-challan for traffic violator using picode. In 2017 International Conference on Intelligent Computing and Control Systems (ICICCS) (pp. 810-813). IEEE.

[5] S Onah, K. (2018). DESIGN AND IMPLEMENTATION OF TRAFFIC OFFENCE TRACKING SYSTEM (Doctoral dissertation, Godfrey Okoye University Ugwuomu Nike, Enugu).

[6] Welekar, A. R., Dahake, R. S., Bodhane, S. M., Wawre, T. B., Umbarkar, R. P., \& Ghormode, P. S. (2018). Analysis of Rules Violation \& Efficient E-Challan Generation Using OCR In Real Time Traffic.

[7] Jichkar, N., Deulkar, A., Thakare, A., Bolakhe, S., \& Vaidya, S. A Novel Approach for Automated E-challan Generation using QR Code and OCR.

[8] Dambe, A., Gandhe, U., \& Bendre, V. (2013). Automatic penalty charging for violation of traffic rules. International Journal of Advanced Research in Electrical, Electronics and Instrumentation Engineering, 2(2).

[9] Biswas, R., Beed, R. S., Seth, D., Pal, P., Basu, K., \& Mukherjee, T. (2015). Traffic Rule Violation Information System TRuVIS. International Journal, 5(7).

[10] Lonkar, B. B., Sayankar, M. R., \& Charde, P. D. (2018, April). Design and Monitor Smart Automatic Challan Generation Based on RFID Using GPS and GSM. In Proceedings of $3 \mathrm{rd}$ International Conference on Advances in Internet of Things \& Connected Technologies (ICIoTCT). 